\title{
Contributions of Weather and Fuel Mix to Recent Declines in U.S. Energy and Carbon Intensity
}

\author{
W. Bart Davis ${ }^{\mathrm{a}, \mathrm{b},{ }_{*}, \text { Alan H. Sanstad }}{ }^{\mathrm{a},{ }^{*} \text {, and Jonathan G. Koomey }}{ }^{\mathrm{a}}$ \\ a Energy Analysis Department \\ Ernest Orlando Lawrence Berkeley National Laboratory \\ University of California \\ Berkeley, CA 94720 \\ $\mathrm{b}$ \\ Department of Economics \\ University of California \\ Berkeley, CA 94720
}

\section{ABSTRACT}

A recent (1996-2000) acceleration of declines in energy and carbon intensity in the U.S. remains largely unexplained. This study uses Divisia decomposition and regression to test two candidate explanations - fuel mix and weather. The Divisia method demonstrates that fuel mix does not explain the declines in carbon intensity. The fuel mix, both overall and for electricity generation, became slightly more carbon intensive over the study period (though the slight trend reversed before the end of the period). A regression-based correction to the Divisia indices, accounting for variation in heatingand cooling-degree-days, indicates that warmer weather accounts for about $30 \%$ of the total declines. This leaves declines of more than $2 \%$ per year (and an acceleration of more than $1 \%$ over previous decade) remaining to be explained.

JEL classification: Q43

Keywords: energy consumption, carbon emissions, Divisia

\footnotetext{
* Authors for correspondence at LBNL, MS90-4000, 1 Cyclotron Road: WBDavis@1bl.gov (510) 4864154 and AHSanstad@lbl.gov (510) 486-6433. The authors would like to thank Dr. Lee Schipper for valuable review comments, and Skip Laitner for his unflagging support. This work was supported by the Office of Atmospheric Programs of the U. S. Environmental Protection Agency, and prepared for the U. S. Department of Energy under Contract No. DE-AC03-76SF00098.
} 


\section{INTRODUCTION}

In the latter half of the 1990s, U.S. economic growth accelerated without increases of corresponding magnitudes in energy consumption and carbon emissions. As a result, aggregate indices of carbon and energy intensity, which are ratios of economy-wide energy use and carbon emissions to Gross Domestic Product, also declined at an accelerated rate during this period. ${ }^{1}$ Should it prove to be more than a transitory shift, this phenomenon could have substantial implications for long-run energy trends and for policies to mitigate carbon emissions. It has thus attracted attention from energy and carbon policy analysts.

Broadly, four explanations for the drop in energy or carbon intensity, or both, have been advanced. First, since this period also saw warmer-than-usual weather in the U.S., it is possible that reduced demand for heating energy accounts for the change in energy intensity. In addition, warmer weather reduces aggregate carbon emissions indirectly by reducing the fuel shares of carbon-intensive electricity. Second, a non-weather-related shift in the fuel mix for electricity generation - toward lower carbon sources - may be a contributing factor. Third, the past half-decade has also seen accelerated diffusion of information technology throughout the economy, and corresponding increases in both labor and multi-factor productivity. It is possible that information technology has also contributed to increases in energy productivity, so that more economic output is being

$1 I=E / G D P, G=C / G D P$, where $E$ is aggregate energy consumption, and $C$ is aggregate carbon emissions. 
generated with less-than-proportionate increases in energy use and the accompanying carbon emissions. Finally, sectoral shifts in the economy, particularly in manufacturing, may be resulting in a lower energy-and-carbon-intensive mix of economic activity, with corresponding decreases in the aggregate intensities.

These explanations are not, of course, mutually exclusive, but they have very different implications for policy. Weather and fuel mix changes unrelated to underlying economic trends are more likely to prove transitory and thus have no systematic implications for longer-run trends. By contrast, diffusion of information technology and structural shifts may be reflected in fundamental changes in the U. S. economy's long-run trajectories of energy use and carbon emissions. As a result, analyses of the recent changes have tended to favor one of the "exogenous" or the "endogenous" explanations to the exclusion of the other.

This paper focuses on the role of weather and fuel mix changes in explaining the recent intensity declines. Specifically, we quantify the effects of fuel mix and weather on energy and carbon intensity using a Divisia index decomposition incorporating a weather correction. We use data from the U. S. Energy Information Administration (EIA) including preliminary data for 1999 and 2000. Our numerical comparisons are between the "study period" 1996 through the first half of 2000 and the previous decade, 1986-96. Our key findings are two-fold:

(1) Changes in fuel mix explain very little of the decreases in $I$ or $G$. Over the entire period 1996-2000 the fuel mix in fact became more carbon intensive, both overall and for electricity generation. During 1999 the trend reversed, toward 
lower carbon intensity, but only enough to compensate for about half the earlier increase. The overall effect of fuel mix on aggregate carbon intensity is an order of magnitude smaller than the total cumulative decline resulting from all sources from 1996 to 2000 .

(2) Warmer weather had a larger effect on both intensity shifts, but still accounted for only about $30 \%$ of the total cumulative declines in energy and carbon intensity. In terms of rates of decline, after correcting for weather effects both energy and carbon intensity still declined at an average rate of more than $2 \%$ per year during the study period, approximately double the rates of the previous decade. That is, although weather mitigates the difference, there was still a substantial acceleration in the rate of decrease of energy and carbon intensity.

An important qualification to these conclusions is that the EIA data are continuing to be revised, specifically for non-utility generation in the electric power sector. Thus, in addition to reaching the primary conclusions noted above, we also consider the effects of including currently-available non utility generation data. This work is preliminary because of limitations on the availability and consistency of these data, and requires certain simplifying assumptions. With this caveat, we find that incorporating these data into the analysis has a relatively large effect on absolute intensity levels, reducing the rates of decline in intensity by about 0.4 percentage points per year, but little effect on the difference in the rates of change of intensity during the study period and the previous decade. That is, in our analysis inclusion of non-utility data apparently does not help explain the acceleration of intensity declines 1996-2000. 
These results should serve to clarify and focus the discussion of recent trends in energy and carbon intensities by indicating the appropriate "mix" of the competing explanations we summarized above. In our view, they highlight the importance of better understanding how rapid economic changes related to information technology may be affecting energy and carbon trends.

The paper is organized as follows. We begin with a review of recent intensity trends and efforts to explain them. Next we describe our application of the Divisia method, provide an overview of recent underlying trends in energy, fuels, and intensities, and present indices for the fuel mix effect on these trends. Following that, we estimate weather corrections for natural gas and electricity, and apply them to generate weather-corrected indices. After presenting our primary results, we discuss the consequences of an approximate adjustment that takes account of non-utility electric power generation. We next discuss the implications of findings for explaining recent trends - particularly the role of technological change, and end with concluding remarks.

\section{RECENT ENERGY AND CARBON TRENDS, AND POSSIBLE EXPLANATIONS}

From 1996 through the first half of 2000 the average annual decreases in energy and carbon intensities in the United States have increased, to more than 3\% per year. This is a marked shift from the trends of the previous decade (1986-96) when the decreases in these intensities were on the order of $1 \%$ annually. The decline in energy intensity exceeds even the average decline during the "oil shock decade" after 1973. Moreover, this change occurred with stable or even declining energy prices in most categories until 
the end of 1999 and the beginning of 2000. These trends in energy use, carbon emissions, and their intensities are represented in Table 2.1, which summarizes the data for primary fossil energy through mid-2000. As the table indicates, the intensity declines are not due merely to an acceleration of economic growth, but also to a slowing in growth of energy use and carbon emissions.

\section{$<<$ insert Table 2.1 $>>$}

The energy consumption average over the period 1996-00 encompasses both very low growth rates during 1997 and 1998 and an increase in 1999 (1.7\%) that is closer to the historical trend. However, energy consumption during the first half of 2000 exceeded that during the first half of 1999 by a more modest $1.2 \%$.

In explaining these patterns, the U. S. EIA has emphasized the influence of transitory changes in weather and the fuel mix to electric power generation. Hakes (2000) argued that the 1997 and 1998 declines in delivered energy resulted almost entirely from a decrease in the residential, commercial, and industrial sectors' use of natural gas. In turn, he attributed this decline to warmer-than-usual weather, and suggested that weathernormalized gas use had actually increased from 1996 to 1998. In accounting for the low increase in 1999 carbon emissions (1\% over 1998), EIA (US DOE 2000b) model simulations indicated that both warmer weather and a jump in nuclear electricity generation had suppressed these emissions relative to normal baselines. More specifically, in these simulations a reversion of weather and nuclear output to the assumed "normals" (as well as a lesser effect due to hydroelectric output) would have resulted in an additional 1.5\% growth in emissions in 1999, so that the total growth for 
that year would have been on the order of $2.5 \%$.

The Council of Economic Advisers (2000) emphasized the importance of structural change - a change in the mix of economic activity among sectors - in conjunction with weather effects. The Council reported the results of a statistical analysis showing that unusually low carbon emissions in 1998 could be ascribed to reduced output in "nonhigh-technology" sectors along with the warmer-than-usual weather. This effect was distinguished from that of underlying efficiency gains. Instead, the finding on changing output mix was interpreted as "[suggesting] that short-term technological change independent of these factors was not an important determinant of...1998 emissions."2

Romm et al. (1999) and Romm (2000) have given a rather different accounting for these trends, focusing on information technology (IT) and the rapid expansion of the Internet in the mid-1990s. These analysts also conclude that the intensity declines are in part to structural changes - a shift in overall activity to the less energy-intensive IT-related sectors. In addition, however, they argue that the declines reflect efficiencies that reduce the energy use per unit of output of goods and services in particular sectors due to the diffusion of information technology and the expansion of the Internet. In this view, the changes in aggregate energy and carbon trends are not merely non-transitory, but may accelerate in the coming years.

\footnotetext{
${ }^{2}$ Council of Economic Advisers (2000), Box 7-1. The Report provided no details on the data or methods employed.
} 
The latter conclusion is generally supported by the findings of Boyd and Laitner (1999), who conducted an index-number analysis of several aggregate energy intensity measures through 1998. Their analysis found a substantial contribution of structural change to the decline in intensities, but also evidence of aggregate increases in energy efficiency due to productivity improvements embodied in new capital. In addition, these conclusions were robust when short-term weather effects were taken into account.

The analysis described in this paper is most closely related, in terms of method, to that of Boyd and Laitner. It extends that work by including preliminary data for 1999 and 2000, including a fuel mix correction, and applying a more detailed weather correction. We now turn to presenting the Divisia index we will use in this paper, describing the data, and presenting results on the fuel mix effect.

\section{DIVISIA DECOMPOSITION OF FUEL MIX EFFECTS}

\section{Methods}

The Divisia decomposition is one of several methods for constructing indices of the contribution of changes in share-weights to changes in share-weighted averages. In the application of this method described in this paper, the whole-economy aggregate carbon emissions intensity is expressed as fuel-share weighted average of fuel emissions intensities. Application of Divisia decomposition then allows the quantification of the contribution of changes in fuel shares to aggregate carbon emissions intensity.

The Divisia index technique is an accounting rather than a statistical method. Error is introduced only through approximation, and this approximation error is small (and 
quantifiable). In addition, this technique - like all index number methods - does not provide for the theoretical explanations that are obtained by applying economic models of optimizing behavior. However, in the present application, this relative limitation may actually be an advantage: if indeed fundamental economic relationships in the economy are changing, then economic models parameterized on data from earlier times might not correctly account for recent energy and carbon trends.

Index methods have been widely applied to studying energy use and carbon emissions trends. ${ }^{3}$ The current research includes two elements that distinguish it from earlier applications. First, aggregate fuel trends are usually calculated by disaggregating energy use by sector and calculating "structure" terms, i.e., changes in sectoral activity shares. There is, however, an approximately two-year lag between the EIA's release of aggregate energy consumption data and the corresponding sectoral breakdowns (in the various detailed Consumption Surveys). For analyzing recent trends, we therefore use a Divisia decomposition that allows calculation of fuel share and emissions rate terms without sectoral activity terms or energy use disaggregated by sector.

Second, we annually lag monthly and quarterly observations to identify the seasonal (weather) component of aggregate energy consumption and carbon emissions and the corresponding indices $I$ and $G$. This provides a seasonally smoothed Divisia decomposition, which eliminates seasonal variation from monthly and quarterly energy data, and extracts a longer-term trend based on adjusted year-to-year changes.

\footnotetext{
${ }^{3}$ See, for example, Boyd et al (1987), Howarth et al. (1991), Krackeler et al. (1998), Unander et al. (1999).
} 
The Divisia equation describes changes in carbon intensity $G$ as a product of changes in energy intensity $I$, and carbon-share-weighted $c$ changes in fuel shares $e$ and emissions rates $R$. The decomposition yields best results when the changes are small, so such indices are commonly "chained" to reduce approximation error. (Further details are provided in the Appendix.)

$$
\frac{G_{T}}{G_{0}}=\prod_{t=1}^{T}\left\lfloor\frac{I_{t}}{I_{t-1}} \prod_{j}^{F}\left(\frac{e_{j, t}}{e_{j, t-1}} \frac{R_{j, t}}{R_{j, t-1}}\right)^{\left\langle c_{j}\right\rangle}\right\rfloor
$$

This approach is commonly applied to annual data, where the observations are incremented one year at each time step. Applying this method to seasonal data, however, introduces some new problems. Seasonal changes are larger than annual ones. The large variation increases the error of approximation, and also increases the influence of the choice of the base period. This study applies a method for seasonal smoothing of quarterly data that mitigates these problems.

Seasonal smoothing is accomplished by annually lagging the differences, then taking the $4^{\text {th }}$ root to convert the annual to quarterly changes, so multiplying four such changes together results in the correct annual index.

$$
\frac{G_{T}}{G_{0}}=\prod_{t=4}^{T} \sqrt[4]{\frac{I_{t}}{I_{t-4}} \prod_{j}^{F}\left(\frac{e_{j, t}}{e_{j, t-4}} \frac{R_{j, t}}{R_{j, t-4}}\right)^{\left\langle c_{j}\right\rangle}}
$$

A similar decomposition provides the Divisia indices for the contribution of fuel shares to the carbon intensity of electricity generation. 


$$
\begin{gathered}
\frac{R_{T}}{R_{0}}=\prod_{t=1}^{T}\left[\prod_{j}^{F_{e}}\left(\frac{e_{j, t}}{e_{j, t-1}}\right)^{\left\langle c_{j}\right\rangle}\right\rfloor \\
\frac{R_{T}}{R_{0}}=\prod_{t=12}^{T} \sqrt[12]{\prod_{j}^{F_{e}}\left(\frac{e_{j, t}}{e_{j, t-12}}\right)^{\left\langle c_{j}\right\rangle}}
\end{gathered}
$$

All data necessary for the electricity generation decomposition are available monthly, so an annual lag equals 12 time steps. It is these chained index terms on the right-hand side of equations (1)-(4) that are charted in the Measures and Findings subsection. A derivation of these equations is provided in the Appendix.

\section{Data}

The energy data used in this analysis were obtained from the EIA's July 2000 Monthly Energy Review (MER) (US DOE 2000a). Primary fuel data are given in MER Table 1.4. The monthly totals for coal, petroleum products, and natural gas were separated into electric utility and non-electric sub-totals by subtracting from these fuel totals the utility consumption figures for fossil fuels in MER Table 2.6. The implied treatment in the MER of these fuels for non-utility electricity generation is discussed in Section 5, below. These monthly data were aggregated to quarterly for comparison with the GDP data (which are not available on a monthly basis).

For non-electric uses, the following (constant) fuel-specific carbon emissions factors (in MtC per quad) were applied: coal, 25.8; petroleum, 19.4; gas 14.5. Emissions factors for electricity were calculated as fuel-share-weighted average emissions factors; in this case, 
21.2 MtC/quad was used for petroleum.

Figure 3.1 charts primary energy consumption, and clearly reveals seasonal cycling. Primary energy use peaks in the winter in the U.S., at more than 2 quads higher than the spring quarter. If seasonal variation is taken to be all additional consumption above the spring minima, then this amounts to about 3-4 quads per year.

$<<$ insert Figure 3.1 $>>$

Figure 3.2 breaks down primary energy consumption into its fuel components, where electricity is reported as an end use fuel in comparable units (quads per quarter).

$<<$ insert Figure 3.2 $>>$

This figure illustrates that the winter peak in total energy consumption is due to increased consumption of natural gas. Oil use is always at a minimum during winter (and fluctuates very little), and electricity use peaks in the summer. When observed on a regional basis, this indicates that the seasonal fluctuation in demand for natural gas can be largely attributed to increased heating demand in the East and North during winter, and for electricity demand increased cooling demand in the South and West during the summer. About 2-3 quads of the total fluctuation is gas, and about 1 quad is electricity.

Table 3.1 summarizes the average annual growth rates for fuel consumption for the study period, and for comparison also includes the growth rates for the previous decade.

$$
<<\text { insert Table } 3.1>>
$$

While non-electric use of coal shows the greatest decline, this is a small share of the total 
non-electric fuel mix. The growth rate of non-electric petroleum demand-primarily transport - increased. Both non-electric gas and electricity rates declined. Because natural gas consumption is the most sensitive to weather changes, followed by electricity, the latter declines lend support to the importance of weather changes in explaining the aggregate intensity declines.

Figure 3.3 charts carbon emissions by fuel, which is calculated by multiplying fuel consumptions by emissions rates. The carbon emissions rate of electricity generation is calculated as the fuel-share weighted average emissions rate of fuels used by electric utilities, while all other emissions rates are the fuel-specific rates calculated by EIA.

$<<$ insert Figure 3.3 $>>$

Energy use by itself does not measure efficiency or productivity. Efficiency measures are rates, expressed in terms of energy use per unit output. For the whole economy, a commonly used measure of output is Gross Domestic Product (GDP). In the U.S., GDP growth has been relatively constant (and rapid) throughout the latter part of the last decade. GDP is the intensity denominator, and quarterly fluctuations are modest. Seasonal fluctuations in $I$ and $G$ are predominantly due therefore to fluctuation in $E$, not in $Y$. The $4.5 \%$ growth of GDP exceeds the $1 \%$ growth of $E$, and so $I$ drops over the period. For comparison, over the decade previous to this period GDP grew at an annual average rate of $2.8 \%$. GDP growth has increased, without a corresponding increase in energy and carbon growth. The extent that fuel mix and weather explain this divergence is the topic of the next section.

\section{Measures and Findings}


Energy and carbon intensities are the aggregate measures we wish to examine with the Divisia decomposition. Figure 3.4 charts both measures.

$<<$ insert Figure 3.4>>

From the figure it can be seen that these two measures track each other closely. The seasonal fluctuation of both also tracks $E$ closely, as expected. As a result, $I$ and $G$, while declining in the long run, actually increase slightly in most quarters except spring, where the drop from winter is large, making up for and exceeding the smaller increases in the first three quarters. It is important that analysts recognize these seasonal variations when making projections from short-term data. The seasonal variations are larger than the underlying long-run trend ( $\sim 10 \%$ compared to $\sim 3 \%)$.

Figure 3.5 presents our first Divisia decomposition, of carbon intensity into fuel mix and energy intensity terms. This chart is based on the equation (1). The two lower indices chart the relative, cumulative percent changes in energy intensity $I$ and carbon intensity $G$ from the base year (1996). The difference between the $G$ and $I$ indices is, by the Divisia equation, multiplicatively decomposed into the other six fuel mix indices above; the product of all indices (except the $G$ index) in each time period is equal to the $G$ index. ${ }^{4}$

$<<$ insert Figure 3.5>>

4 More accurately, the ratio of the $G$ and $I$ indices is multiplicatively decomposed into the remaining six indices (and is equal to their product). For small changes, the difference closely approximates this ratio. 
From Figure 3.5 we can again see that the seasonal effects are large. This chart illustrates some problems with applying the standard chained Divisia decompositions with one period lags to quarterly data. Most importantly, the use of the first quarter as a base period carries a large relative one-quarter decrease forward throughout the study period, resulting in an exaggerated estimate of the decrease in energy and carbon intensity (1996 happened to be an unusually cold winter). The large variation also increases the approximation error (increasing the "residual" of decomposition).

Figure 3.6 applies equation (2) to smooth out the seasonal effects, presenting indices of long-run changes in energy and carbon intensity. This smoothing is accomplished by calculating the percent changes in all variables relative to the same variable in the previous year, rather than the previous quarter (then taking the fourth root to convert the annual change to quarterly). This approach eliminates seasonal variation, resulting in smooth indices of long-run changes. The product of all indices in any year except $G$ is still equal to $G$.

$<<$ insert Figure 3.6>>

From Figure 3.6, it is evident that both $I$ and $G$ decreased $11-12 \%$ during the study period. The carbon intensity index $G$ is always higher than the energy intensity index $I$, indicating that the fuel mix has become more carbon intensive during this period. The electricity generation index indicates that the generation of electricity has also become more carbon intensive. Fuel share index terms are the carbon-share-weighted growth rates of fuel shares, increasing when the (relative) use of that fuel increases, and vice versa. Without the electricity generation term, the contribution of the remaining fuel 
share indices (when aggregated multiplicatively) is close to zero, i.e., the difference between $G$ and $I$ can be explained entirely by the increase in carbon intensity of electric generation.

The Divisia decompositions of the fuel mix for electricity generation described in equation (4) provide the basis of Figure 3.7.

\section{$<<$ insert Figure 3.7>>}

Over the whole period electricity generation became about $3 \%$ more carbon intensive. An increase in the coal share propelled growth in 1997-98, then an increase in the oil share combined to provide the most intensive generation in late 1998, 4\% higher than two years previous. In 1999 oil substituted for coal until recently, when coal again replaced oil, but first the declining coal share then a declining oil share lead to a slightly less carbon intensive generation mix by 2000, still 3\% higher than in 1996.

The results presented in figures 3.6-3.9 provide evidence against the hypothesis that changes in the fuel mix can explain recent decreases in carbon intensity. All fuel mix terms are small, and some of the energy savings do not translate into carbon savings because the electricity share has actually increased slightly over the period, as has the carbon emissions rate for electricity generation, due to the increased generation share of fossil fuels. Even after correcting for fuel mix, and especially after correcting for 
seasonal fluctuations, the stark downward trend in energy and carbon intensity remains unexplained. ${ }^{5}$

\section{ESTIMATION OF WEATHER EFFECTS}

\section{Methods}

The approach taken to estimate the fuel consumption effects of weather variations involves: (1) fitting statistical models of gas and electricity demand as a function of heating- and cooling-degree days (HDD, CDD), and disposable household income; (2) using these fits to estimate what gas and electricity demand would have been had the weather (heating- and cooling-degree days) been "normal" (equal to the 1961-90 average); and (3) recalculating the Divisia indices based on these weather-adjusted demand estimates, and comparing. The fitting technique is ordinary least squares.

\section{Data}

5 This finding is not necessarily inconsistent with the EIA's conclusion that a jump in the nuclear contribution moderated carbon output in 1999. The reason is that increasing nuclear generation cannot explain the carbon intensity change over the entire 1996-2000 period. Nuclear generation in kilowatt hours was lower in both 1997 and 1998 than in 1996, and as a share of total net generation was lower in both 1997 and 1998 than in any year since 1989 (US DOE 2000a). 
In addition to monthly U.S. gas and electricity consumption, average (populationweighted) HDD and CDD are required, as are the averages for 1961-1990. These data are also contained in the Energy Information Administration's Monthly Energy Review series.

The study period saw warmer than average winters. January 1998 was particularly warm, and the warmer winter period grew longer, so total HDD decreased throughout 19962000. The warming trend produced a discernible decrease in heating demand. A weaker corresponding increase in cooling demand is also evident, though the trend is not statistically discernible from zero.

Total personal disposable income was acquired from the BEA website, and grew steadily throughout the period.

All models were estimated using monthly data from January, 1986 to June 2000.

\section{Results}

\section{Natural Gas Model}

Table 4.1 summarizes the results for the natural gas regression.

$<<$ insert Table 4.1 $>>$

The whole-model fit is very good, and the effects of the coefficients are each strongly discernible. The intercept coincides with the annual minimum in 1986. The coefficient 
on HDD estimates that 870 heating-degree days will result in 1 quad of natural gas consumption. Income is very closely correlated with time ( $\rho=0.995)$, so the t-ratio on income also indicates a discernible time trend.

The natural gas model does not capture the small summer bump due to gas air conditioning ( $\mathrm{CDD}$ is not included in the regression), and it tends to under predict the peak demand slightly. Otherwise it performs well predicting demand during the 19962000 period.

\section{Electricity Model}

Table 4.2 summarizes the results for the electricity regression.

$$
<<\text { insert Table } 4.2>>
$$

Again, the whole-model fit is very good and all coefficients are discernible from zero. Because CDD and HDD are inversely correlated, an independent interpretation of the coefficients is problematic.

The electricity model does capture the small winter bump due to electric heating (both HDD and CDD are included in the regression), and it does a better job of predicting peak demand.

\section{Weather Correction Indices}

Adjusting the Divisia indices to reflect a weather correction entails: (1) using the statistical models described in the previous section to estimate what fuel consumption would have been had HDD and CDD during 1996-2000 been the same as the average of 
1961-1990, and (2) recalculating the indices based on this "weather-adjusted" consumption.

The weather adjustment is the difference between actual and predicted fuel use. Warmer than average weather causes a downward adjustment to fuel consumption in winter, and an upward adjustment in summer. For gas, the downward winter adjustment exceeds the upward summer adjustment, and the net effect of warmer weather is reduced annual demand. Furthermore, this downward adjustment has been increasing in magnitude, as weather has been increasingly warmer. For electricity, the net effect of warmer weather is negative, although smaller in magnitude than the gas effect. The net effect of warmer weather on total energy consumption is therefore negative - less energy is consumed in aggregate.

These weather adjustments are applied to gas and electricity consumption, and the indices recalculated. The adjusted indices are charted in Figure 4.1.

$$
<<\text { insert Figure 4.1 }>>
$$

The difference between energy and carbon intensity is the product of the fuel share and electricity generation indices. The fact that $\mathrm{G}$ and I track so closely is a result of the small effect of changes in fuel shares, with or without the weather adjustment.

Adjusted for weather, energy and carbon intensity have both decreased 9\% during the study period, at close to $2 \%$ per year. Exact figures are provided in Table 4.3.

$$
<<\text { insert Table 4.3>> }
$$


Warmer weather has accounted for a little more than $3 \%$ of the decrease in energy intensity during the study period, and a little less than $3 \%$ of the decrease in carbon intensity. The declining share of natural gas due to reduced heating demand explains the difference (the weather has the largest effect on natural gas use). Table 4.4 provides the exact figures.

$<<$ insert Table 4.4>>

To summarize, for a given aggregate energy intensity, carbon intensity varies with the consumption shares of fuels with different carbon emissions rates. A more carbonintensive fuel mix will result in more carbon emissions for the same level of energy consumption. The fuel mix causes the difference between indices of energy and carbon intensity. Weather effects both carbon and energy intensity together. Increasing average temperatures throughout the 1990s resulted less winter heating demand (and more summer cooling). Since energy demand in the U.S. peaks in winter, the net effect was reduced aggregate energy consumption and carbon emissions.

Figure 4.2 summarizes these effects, in relative terms (using indices). The fuel mix effect is calculated using Divisia decomposition, and the weather effect using regression of energy demand on heating- and cooling-degree days.

$<<$ insert Figure 4.2>>

This figure most concisely summarizes the results of the paper. The fuel mix explains the difference between energy and carbon intensity - the C/GDP index is the E/GDP index multiplied by the fuel mix index, and thus this same effect can be observed in two 
different places on the chart. The observed energy and carbon intensity includes the charted weather effect. Hotter weather accounts for about one-quarter the observed decreases in energy and carbon intensity in the U.S. from 1996-2000, and changes in the fuel mix have resulted in a slight increase in carbon intensity during this period.

\section{NONUTILITY GENERATION}

Due to the recent restructuring of the electric power industry, utilities have been divesting their generation assets, resulting in reclassification of generation as non-utility generation (NUG). The share of non utility generation has been increasing rapidly in recent years, from $12 \%$ in 1996 to $20 \%$ in the first 8 months of 2000 . Recently EIA has introduced a new survey instrument, to better measure the non utility generation of electricity.

It is difficult to directly incorporate the new EIA data on NUG into the existing calculations. For the Divisia decomposition, the frequency of the observations must be no less than quarterly (monthly in some cases). Observations on NUG have only been this frequent since 1999. Monthly interpolation of annual observations from 1996-98 is very uncertain. Also, since NUG presents particular measurement difficulties, and EIA is still working to adequately incorporate NUG into their overall framework, there still exist some apparent inconsistencies between the NUG data and other EIA data.

Unfortunately, since primary coal, oil, and gas (COG) is calculated as the difference between total primary COG and utilities COG, and especially since non utility generation has been growing so quickly, this exclusion (a) understates electricity demand relative to other primary fuels, and (b) understates the contribution of electricity fuel share and 
emissions rate to aggregate energy and carbon intensity. Insofar as the emission rate of non utility generation may differ from utility generation, this exclusion may also bias the electricity generation contribution to decreases in carbon intensity. Finally, NUG primary fuel consumption includes that for cogeneration, while utilities primary fuel consumption excludes cogeneration. This makes NUG appear slightly more energy and carbon intensive. It may be, therefore, that inclusion of NUG substantially affects the results of the previous sections. The remainder of this section considers the magnitude of the effects of inclusion of NUG on the previous results.

\section{Data}

Non utility consumption of coal, oil, and gas are provided in MER Table 7.8.

"Consumption" of non fossil resources to generate electricity is calculated from Table

7.4, using the heat rates implicit in the conversion for utility non fossil generation (T2.6 / T7.2).

\section{Methodology}

Estimating the sensitivity of the results to the inclusion of NUG requires some assumptions and approximations. The Divisia methodology of the previous sections requires quarterly data, and data on NUG prior to 1999 are only available annually. The annual data were interpolated to quarterly by applying the quarterly shares of NUG (of the annual total) from 1999-2000 to the annual observations prior to 1999 . With this interpolated data, the Divisia methods of section 3 were repeated.

\section{Resolution of Apparent Discrepancy}


If non electricity fuel consumption is calculated as total (T1.4) minus utilities (T2.6) minus non utilities (T7.8, with a units conversion), then non electricity coal becomes negative in 2000 (electricity coal appears to exceed total coal). Assuming that non utility consumption was not properly included in the totals in T1.4 (and adding it in) resolves this problem, resulting in a reasonable answer for non electricity coal.

\section{Results}

The addition of non utility consumption increases absolute energy consumption and carbon emissions. This inclusion increases the annual average spring growth in electricity to $3.7 \%$ throughout $1986-96$, and to $3.1 \%$ in $1996-2000$. The increase in energy consumption also increases absolute intensity, so the intensity indices do not decrease as fast. This is indicated in the Figure 5.1, which presents the seasonally smoothed Divisia indices with the data adjusted for non utility generation.

$<<$ insert Figure 5.1 $>>$

Comparing this figure with Figure 4.1, one can see the effects of adding NUG to the totals. Both carbon and energy intensity show about $2 \%$ less of a decrease over the entire study period. Declines in intensity are about $0.4 \%$ slower per year.

It is important to recognize that NUG was also not included in the intensity indices for the decade previous to the study period. While the inclusion of NUG in this fashion does have a noticeable effect on the intensity indices, it does not have the same effect on the difference between the rates of decline in intensity during the study period and the decade previous, and it is this difference that we are interested in. The inclusion of NUG does 
not explain any of the acceleration in the decline of intensity - it just changes the levels pre and post acceleration.

Inclusion of NUG does, however, have a noticeable effect on the electricity share index, which increased more rapidly in 2000. NUG is growing more rapidly than other fuels, especially recently, so its inclusion increases the electricity share. However, inclusion of NUG in this manner does not noticeably effect the electricity generation fuel share indices (Figure 3.7).

\section{CONCLUDING REMARKS}

Our results indicate that the last half-decade has indeed seen a demonstrable shift in underlying energy and carbon trends not attributable to short-term weather or fuel mix variations - more than a doubling in the rate of intensity declines. These findings lend indirect support to the hypothesis that recent intensity declines may reflect underlying changes in the economy. Neither our data nor our methods allow us to distinguish technological from structural change in the "residual" declines once weather and fuel mix effects are accounted for. However, if these intensity declines are sustained, as we noted in the Introduction, this shift could have considerable implications for energy and carbon policy.

Recent analyses have concluded that the past half-decade acceleration in U. S. economic growth and gains in labor and total-factor productivity can be attributed to the effects of information technology (IT) (Jorgenson and Stiroh 2000, Oliner and Sichel 2000. 
Specifically, rapid technological change in the IT-producing sectors has resulted in a rapid price decline for IT goods, resulting in a substitution toward these goods in other sectors. In particular, the timing of the shifts in aggregate productivity trends coincided with a dramatic acceleration in price declines for IT goods in the mid-1990s.

In this view, the effects of IT in the aggregate do not reflect generalized technological change but instead a more conventional substitution effect due to relative price changes. Other work suggests, by contrast, that IT makes a substantial contribution to productivity growth when measured at the level of individual firms (Brynjolfsson et al. 2000). The existence of this firm-level effect would appear to indirectly support the plausibility of direct energy-productivity gains due to IT. Even the narrower, substitution-based account of productivity improvements, however, is consistent with the hypothesis that the U.S. economy is undergoing a fundamental shift toward greater aggregate energy productivity. Research on technological change and input substitution in the period prior to the mid1990s has previously indicated a pattern, in some sectors, of "information capital" substituting for energy, among other inputs (Stiroh 1998). A reasonable, if preliminary, explanation of our results is that this trend accelerated in the last half of the 1990s. Better understanding of this phenomenon awaits further research. 


\section{APPENDIX: DIVISIA DERIVATION}

Aggregate energy and carbon intensity are ratios of energy and carbon per unit GDP (at date $t$ ):

$$
I_{t} \equiv \frac{E_{t}}{Y_{t}} ; \quad G_{t} \equiv \frac{C_{t}}{Y_{t}}
$$

The aggregate carbon emissions rate is also a ratio:

$$
R_{t} \equiv \frac{C_{t}}{E_{t}}
$$

Aggregate carbon intensity can be expressed as a prodct of aggregate energy intensity and the carbon emissions rate, and the aggregate carbon emissions rate can in turn be expressed as a fuel-share $\left(e_{j, t}\right)$ weighted sum of fuel emissions rates:

$$
\begin{gathered}
G_{t} \equiv \frac{C_{t}}{Y_{t}}=\frac{C_{t}}{E_{t}} \frac{E_{t}}{Y_{t}}=I_{t} \frac{C_{t}}{E_{t}}=I_{t} \sum_{j}^{f} \frac{C_{j, t}}{E_{j, t}} \frac{E_{j, t}}{E_{t}}=I_{t} \sum_{j}^{f} e_{j, t} R_{j, t}, \\
G_{t}=I_{t} \sum_{j}^{f} e_{j, t} R_{j, t} .
\end{gathered}
$$

Changes in aggregate carbon intensity covary with changes in aggregate intensity, and changes in fuel shares and fuel emissions rates. These changes can be expressed as multiplicative indices using Divisia decomposition, by first differentiating both sides of (A1) w.r.t. time,

$$
\dot{G}_{t}=\dot{I}_{t} \sum_{j}^{f} e_{j, t} R_{j, t}+I_{t} \sum_{j}^{f} \dot{e}_{j, t} R_{j, t}+I_{t} \sum_{j}^{f} e_{j, t} \dot{R}_{j, t},
$$


then dividing by $G_{t}$ and rearranging terms to express the growth rates of carbon intensity as a carbon share weighted average of the growth of fuel shares and emissions rates,

$$
\frac{\dot{G}_{t}}{G_{t}}=\frac{\dot{I}_{t}}{I_{t}}+\sum_{j}^{f} c_{j, t}\left(\frac{\dot{e}_{j, t}}{e_{j, t}}+\frac{\dot{R}_{j, t}}{R_{j, t}}\right)
$$

and finally, integrating over time from 0 to $\mathrm{T}$,

$$
\ln \frac{G_{T}}{G_{0}}=\int_{0}^{T}\left[\frac{\dot{I}_{t}}{I_{t}}+\sum_{j}^{f} c_{j, t}\left(\frac{\dot{e}_{j, t}}{e_{j, t}}+\frac{\dot{R}_{j, t}}{R_{j, t}}\right)\right] d t .
$$

This is the Divisia equation. In order to approximate the integral, assume that carbon shares remain constant over time at some average level $\left\langle c_{j}\right\rangle$. Then

$$
\ln \frac{G_{T}}{G_{0}}=\ln \frac{I_{T}}{I_{0}}+\sum_{j}^{f}\left\langle c_{j}\right\rangle\left(\ln \frac{e_{j, T}}{e_{j, 0}}+\ln \frac{R_{j, T}}{R_{j, 0}}\right),
$$

and exponentiating,

$$
\frac{G_{T}}{G_{0}}=\frac{I_{T}}{I_{0}} \prod_{j}^{f}\left(\frac{e_{j, T}}{e_{j, 0}} \frac{R_{j, T}}{R_{j, 0}}\right)^{\left\langle c_{j}\right\rangle}
$$

The index of changes in aggregate carbon intensity is decomposed into multiplicative indices of changes in aggregate energy intensity, and indices of fuel shares and fuel emissions rates. It is typical to assume the carbon share is the midpoint of each time interval,

$$
\left\langle c_{j}\right\rangle=\frac{c_{j, t}+c_{j, t-1}}{2}
$$

known as the "simple average" Divisia. This decomposition yields best results when the 
changes are small, so such indices are commonly "chained" annually, to reduce approximation error. In other words, when implementing (A3) the changes are calculated observation to observation, and the cumulative index (over a longer time period) is calculated as the product of the chain indices:

$$
\frac{G_{T}}{G_{0}}=\prod_{t=1}^{T}\left\lfloor\frac{I_{t}}{I_{t-1}} \prod_{j}^{F}\left(\frac{e_{j, t}}{e_{j, t-1}} \frac{R_{j, t}}{R_{j, t-1}}\right)^{\left\langle c_{j}\right\rangle}\right\rfloor .
$$

Additional seasonal variation in $E_{t}$ causes quarterly changes to be larger than long-run, year-to-year changes. Therefore lagging the changes four periods instead of one produces a "seasonally smoothed" index, and also reduces the error introduced by the approximation of the integral (because carbon shares change less, so the simple average approximation is more accurate),

$$
\frac{G_{T}}{G_{0}}=\prod_{t=4}^{T} \sqrt[4]{\frac{I_{t}}{I_{t-4}} \prod_{j}^{F}\left(\frac{e_{j, t}}{e_{j, t-4}} \frac{R_{j, t}}{R_{j, t-4}}\right)^{\left\langle c_{j}\right\rangle} .}
$$

The fourth root converts the annual change to a quarterly one (so multiplying four such changes together results in the correct annual index).

When implementing (2) it is also assumed that the emissions rates are constant for all fuels other than electricity. An index of changes in the emissions rate for electricity generation can be similarly decomposed into carbon-share weighted relative changes in the shares of primary energy used to generate electricity, as follows:

$$
R_{t} \equiv \frac{C_{t}}{E_{t}}=\sum_{j}^{e f} \frac{C_{j, t}}{E_{j, t}} \frac{E_{j, t}}{E_{t}}=\sum_{j}^{e f} e_{j, t} R_{j, t},
$$




$$
\dot{R}_{t}=\sum_{j}^{e f} \dot{e}_{j, t} R_{j, t}+\sum_{j}^{e f} e_{j, t} \dot{R}_{j, t}=\sum_{j}^{e f} \dot{e}_{j, t} R_{j, t},
$$

(because fuel-specific emissions rates are unchanging). Then

$$
\frac{\dot{R}_{t}}{R_{t}}=\sum_{j}^{e f} c_{j, t} \frac{\dot{e}_{j, t}}{e_{j, t}}
$$

Assuming carbon shares constant and integrating from 0 to $\mathrm{T}$,

$$
\ln \frac{R_{T}}{R_{0}} \approx \sum_{j}^{e f}\left\langle c_{j}\right\rangle \ln \frac{e_{j, T}}{e_{j, 0}}
$$

or

$$
\frac{R_{T}}{R_{0}} \approx \prod_{j}^{e f}\left(\frac{e_{j, T}}{e_{j, 0}}\right)^{\left\{c_{j}\right\}}
$$

Finally this index is again chained quarterly, or annually for seasonal smoothing:

$$
\begin{gathered}
\frac{R_{T}}{R_{0}}=\prod_{t=1}^{T}\left[\prod_{j}^{F_{e}}\left(\frac{e_{j, t}}{e_{j, t-1}}\right)^{\left\langle c_{j}\right\rangle}\right\rfloor, \\
\left.\frac{R_{T}}{R_{0}}=\prod_{t=12}^{T} \sqrt{\prod_{j}}\left(\frac{e_{j, t}}{e_{j, t-12}}\right)^{\left\langle c_{j}\right\rangle}\right] .
\end{gathered}
$$


Table 2.1. Average annual growth rates of primary fossil energy use, carbon emissions, GDP, and associated intensities

\begin{tabular}{|l|c|c|c|c|c|}
\hline AAGRs & $\begin{array}{c}\text { Energy / } \\
\text { GDP }\end{array}$ & $\begin{array}{c}\text { Carbon / } \\
\text { GDP }\end{array}$ & Energy & $\begin{array}{c}\text { Carbon } \\
\text { emissions }\end{array}$ & GDP \\
\hline $1986-96$ & $-0.9 \%$ & $-1.1 \%$ & $2.0 \%$ & $1.7 \%$ & $2.8 \%$ \\
\hline $1996-00$ & $-3.2 \%$ & $-3.2 \%$ & $1.0 \%$ & $1.3 \%$ & $4.5 \%$ \\
\hline
\end{tabular}

NOTE: 1999-2000 growth calculated as growth of January-June 2000 over January-June 1999.

Table 2.1. Recent declines in U.S. energy and carbon intensity were due not only to an acceleration of economic growth, but also to a slowing in growth of energy use and carbon emissions. 
Table 3.1. Fuel Average Annual Growth Rates

\begin{tabular}{|l|c|c|}
\hline & $1986-96$ & $1996-00$ \\
\hline Non-electricity uses & & \\
\hline Coal & $-0.9 \%$ & $-2.2 \%$ \\
\hline Petroleum & $1.4 \%$ & $1.6 \%$ \\
\hline Gas & $3.5 \%$ & $-0.8 \%$ \\
\hline Electricity generation & $2.0 \%$ & $1.7 \%$ \\
\hline Total & $2.0 \%$ & $1.0 \%$ \\
\hline
\end{tabular}

NOTE: 1999-2000 growth calculated as growth of January-June 2000 over January-June 1999.

Table 3.1. Non-electricity coal use declined faster in 1996-2000 than in the previous decade. The change in consumption of non-electricity gas, the fuel most sensitive to changes in the weather, reversed direction, from rapid growth in the reference decade, to slow decrease. Relative to the reference decade, growth of oil use increased slightly, while the growth of electricity generation decreased slightly. 
Table 4.1. Natural Gas Regression Results

\begin{tabular}{|l|ccc||cc|}
\cline { 2 - 6 } \multicolumn{1}{c|}{} & Intercept & HDD & Income & $\mathrm{R}^{\wedge} 2$ & $\mathrm{~N}$ \\
\hline $\begin{array}{c}\text { Coefficient } \\
\text { (t-ratio) }\end{array}$ & $\begin{array}{c}0.67 \\
(35)\end{array}$ & $\begin{array}{c}0.0012 \\
(34)\end{array}$ & $\begin{array}{c}0.0013 \\
(20)\end{array}$ & 0.91 & 174 \\
\cline { 5 - 6 }
\end{tabular}

Table 4.1. Whole-model fit is very good, and the effects of the coefficients are each strongly discernible. The main shortcomings of this simple model are that it does not predict the small summer bump due to gas air conditioning, and it tends to under predict peak demand slightly. Otherwise it predicts U.S. monthly gas demand quite well. 
Table 4.2. Electricity Regression Results

\begin{tabular}{|c|c|c|c|c|c|c|}
\hline & Intercept & CDD & HDD & Income & $\mathrm{R}^{\wedge} 2$ & $\mathrm{~N}$ \\
\hline \multirow{2}{*}{$\begin{array}{l}\text { Coefficient } \\
\text { (t-ratio) }\end{array}$} & \multirow{2}{*}{$\begin{array}{l}1.2 \\
(35)\end{array}$} & \multirow{2}{*}{$\begin{array}{c}0.0030 \\
(35)\end{array}$} & \multirow{2}{*}{$\begin{array}{c}0.00064 \\
(20)\end{array}$} & \multirow{2}{*}{$\begin{array}{c}0.0018 \\
(15)\end{array}$} & 0.94 & 174 \\
\hline & & & & & & \\
\hline
\end{tabular}

Table 4.2. Whole-model fit is excellent, and the effects of all coefficients are strongly discernible. This simple model does an excellent job of predicting U.S. monthly electricity demand during the study period. 
Table 4.3. Smoothed, Weather Adjusted Divisia Indices

\begin{tabular}{|c|c|c|c|c|c|c|c|}
\hline & C / GDP & E / GDP & $\begin{array}{c}\text { Coal } \\
\text { Share }\end{array}$ & $\begin{array}{c}\text { Oil } \\
\text { Share }\end{array}$ & $\begin{array}{c}\text { Gas } \\
\text { Share }\end{array}$ & $\begin{array}{c}\text { Electricity } \\
\text { Share }\end{array}$ & $\begin{array}{c}\text { Electricity } \\
\text { Generatio } \\
\mathrm{n}\end{array}$ \\
\hline 1997Q1 & 0.977 & 0.973 & 0.998 & 1.001 & 0.998 & 1.002 & 1.004 \\
1998Q1 & 0.952 & 0.940 & 0.996 & 1.000 & 0.993 & 1.011 & 1.012 \\
1999Q1 & 0.928 & 0.915 & 0.994 & 0.999 & 0.985 & 1.022 & 1.014 \\
2000Q1 & 0.898 & 0.887 & 0.993 & 1.007 & 0.985 & 1.016 & 1.012 \\
\hline
\end{tabular}

Table 4.3. Corrected for differences in the weather, energy and carbon intensity still decrease steadily and rapidly, at more than $2.5 \%$ per year. Changes in coal and oil share have little effect on carbon intensity. An increasing gas share contributed $1.5 \%$ to the total decrease in carbon intensity, while the increase in the electricity share more than compensated for this difference. Electricity generation became more carbon intensive, although this trend reversed slightly, in parallel with the electricity share, by early 2000 . 


\section{Table 4.4. Weather Adjustment Indices}

\begin{tabular}{|c|c|c|}
\hline & C / GDP & E / GDP \\
\hline 1997Q1 & 0.993 & 0.992 \\
1998Q1 & 0.986 & 0.984 \\
1999Q1 & 0.983 & 0.979 \\
2000Q1 & 0.973 & 0.968 \\
\hline
\end{tabular}

Table 4.4. Warmer weather accounted for a little more than $3 \%$ of the decrease in energy intensity during the study period, and a little less than $3 \%$ of the decrease in carbon intensity. 
Figure 3.1. U.S. Primary Energy Consumption

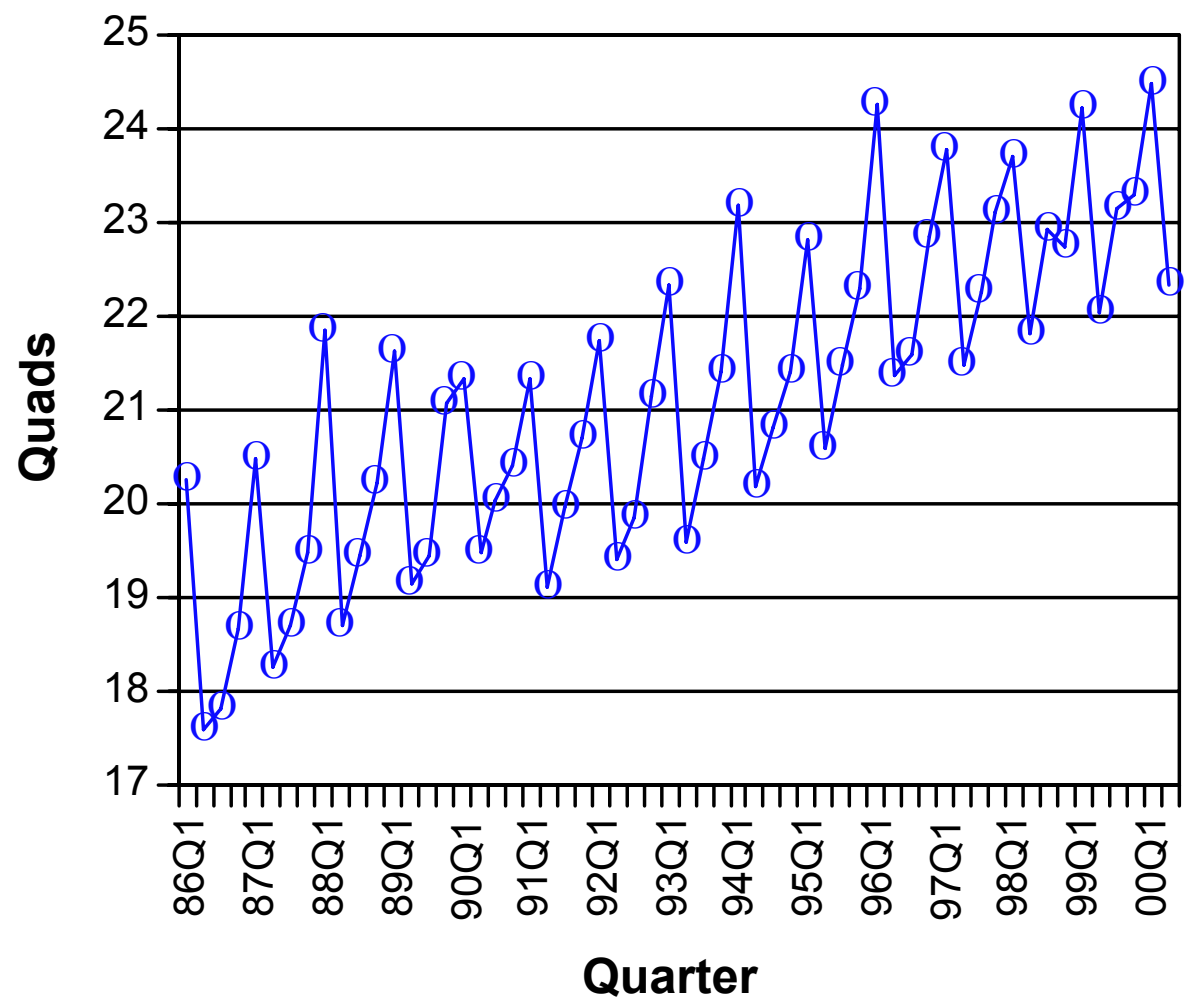

Figure 3.1. U.S. primary energy consumption peaks in the winter. If seasonal variation is taken to be all consumption above the spring minima, then this amounts to 3-4 quads per year. 
Figure 3.2. U.S. Energy End Use by Fuel

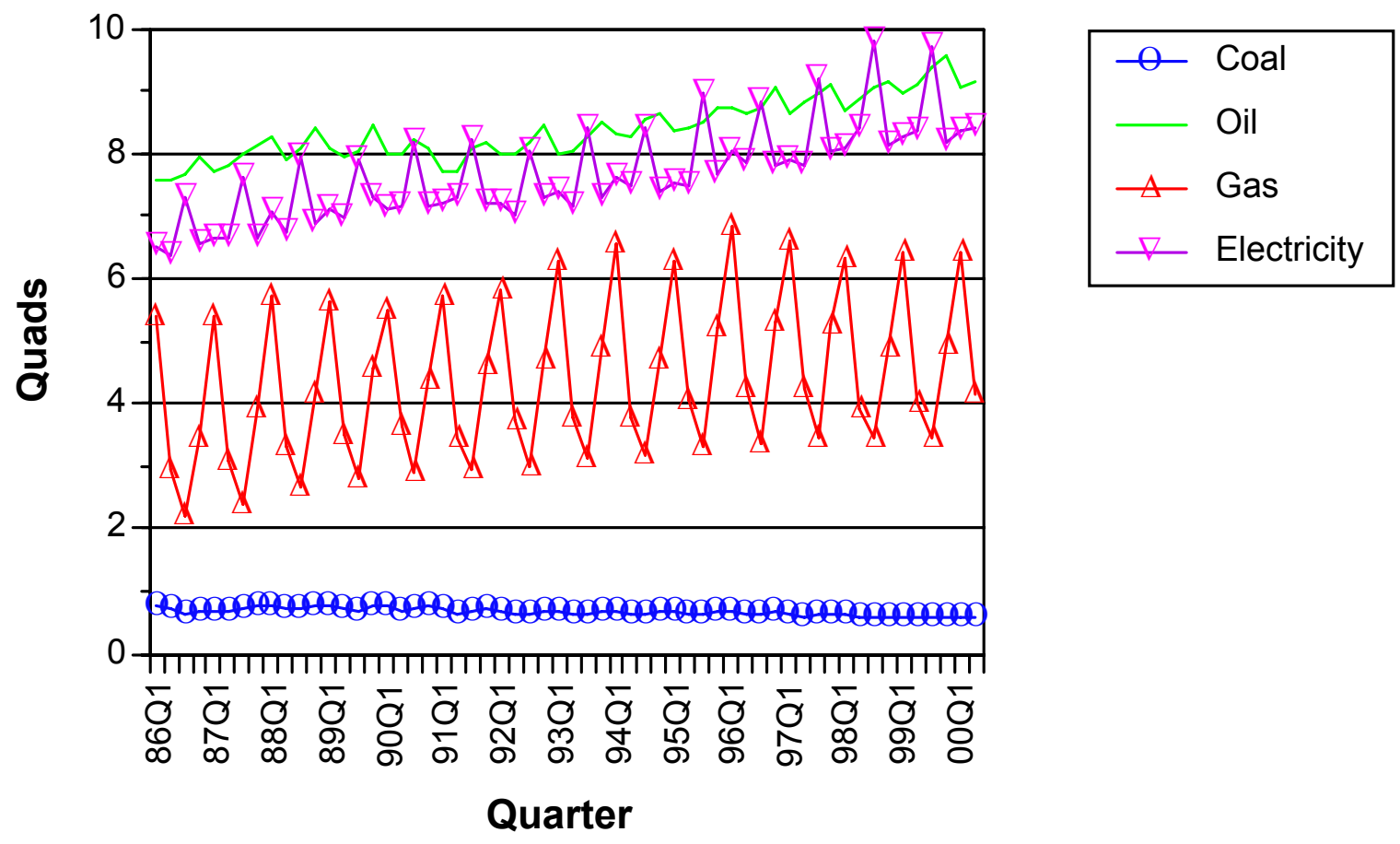

Figure 3.2. Natural gas shows the largest seasonal variation, 2-3 quads per year, peaking in winter due to increased demand for heating in the northern and eastern U.S.. Electricity demand also varies about 1 quad per year, peaking in summer due to increased demand for cooling in the western and southern U.S.. 
Figure 3.3. U.S. Carbon Emissions by Fuel

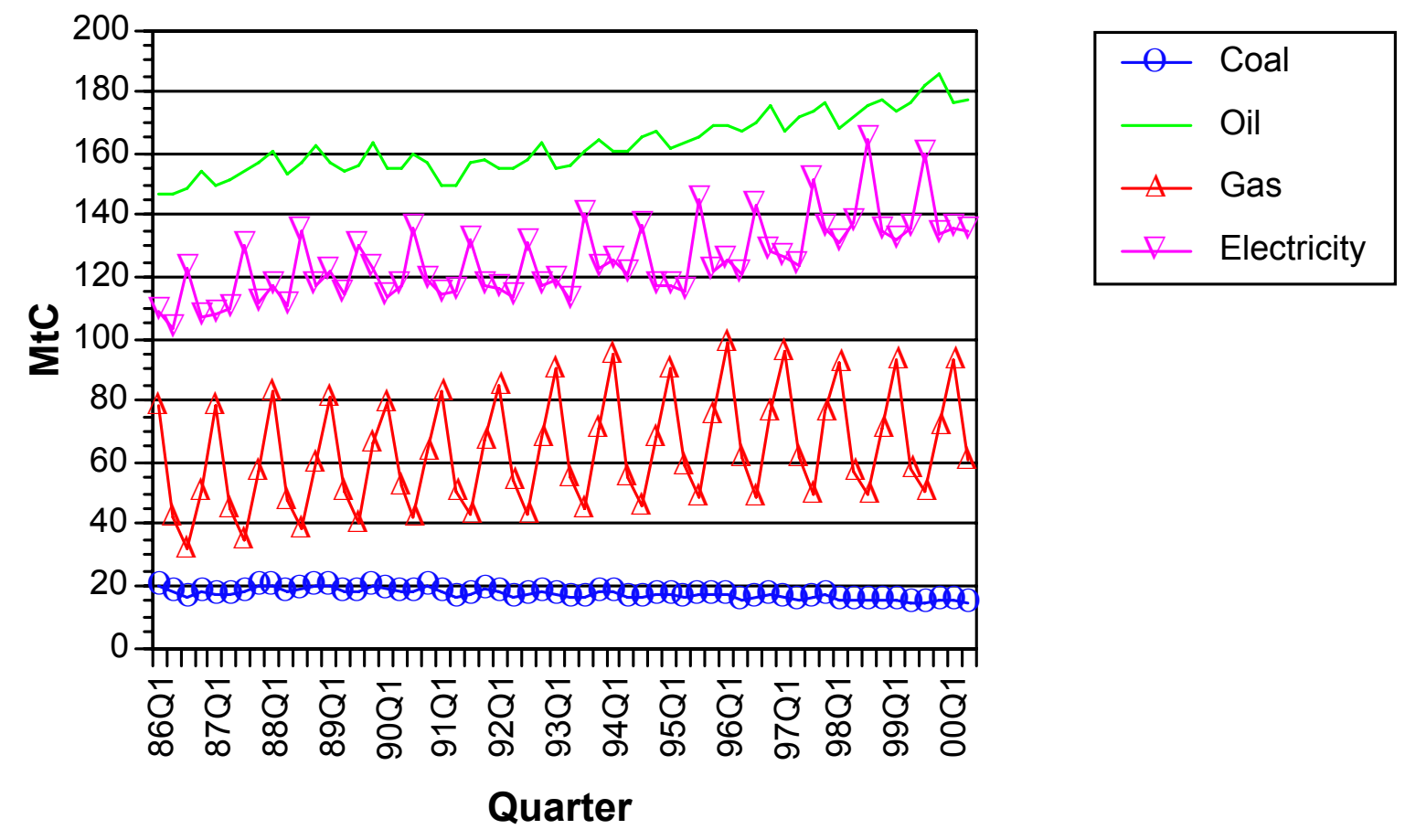

Figure 3.3. Calculated carbon emissions for coal, oil, and gas, are strictly proportional to consumption of these fuels. Calculated carbon emissions for electricity are a function of the fuel shares for electricity generation, which change over time. 
Figure 3.4. U.S. Energy and Carbon Intensity

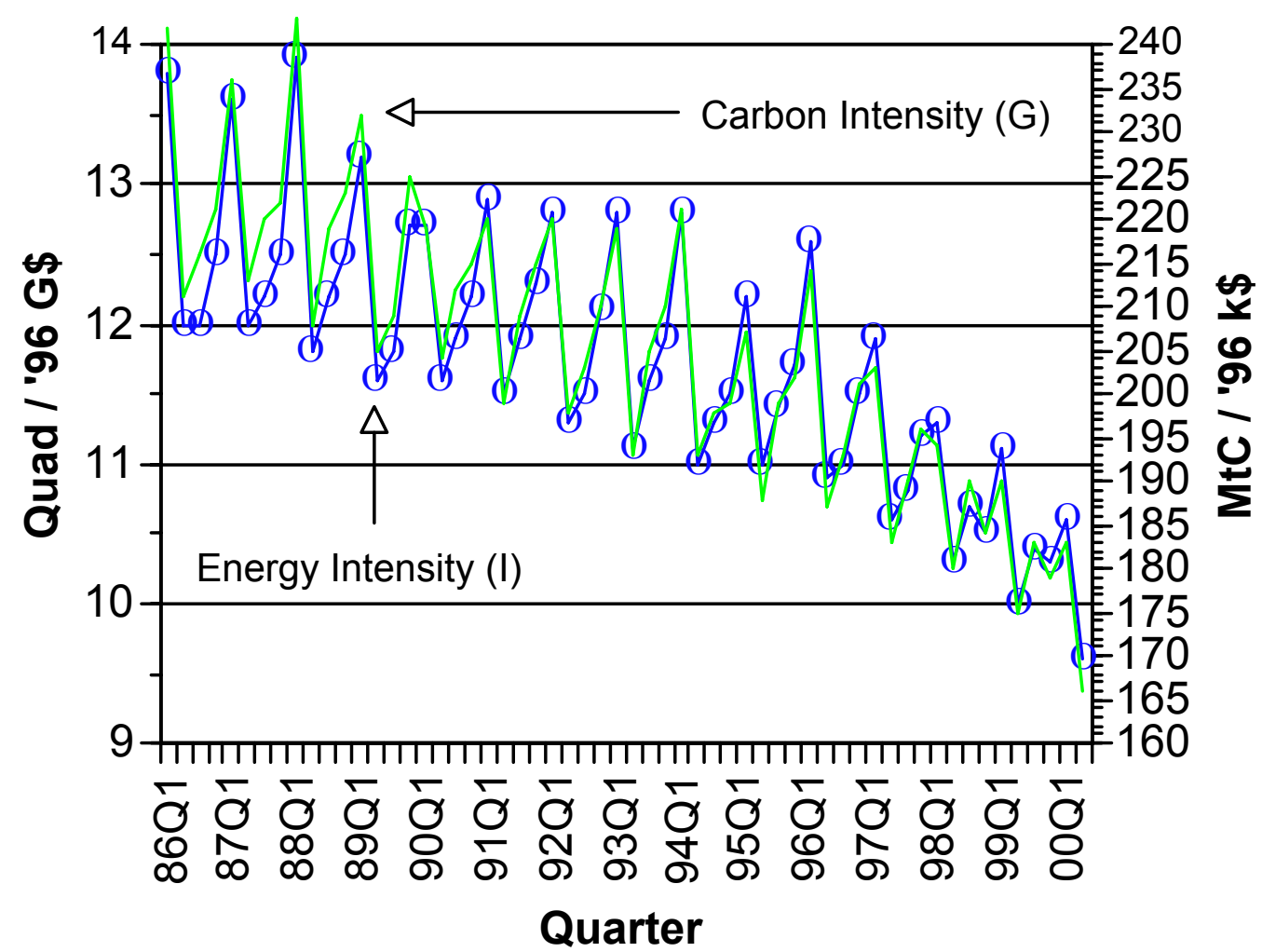

Figure 3.4. The seasonal variation in U.S. energy and carbon intensity decreased, while the rate of decline increased. 
Figure 3.5. Divisia Indices

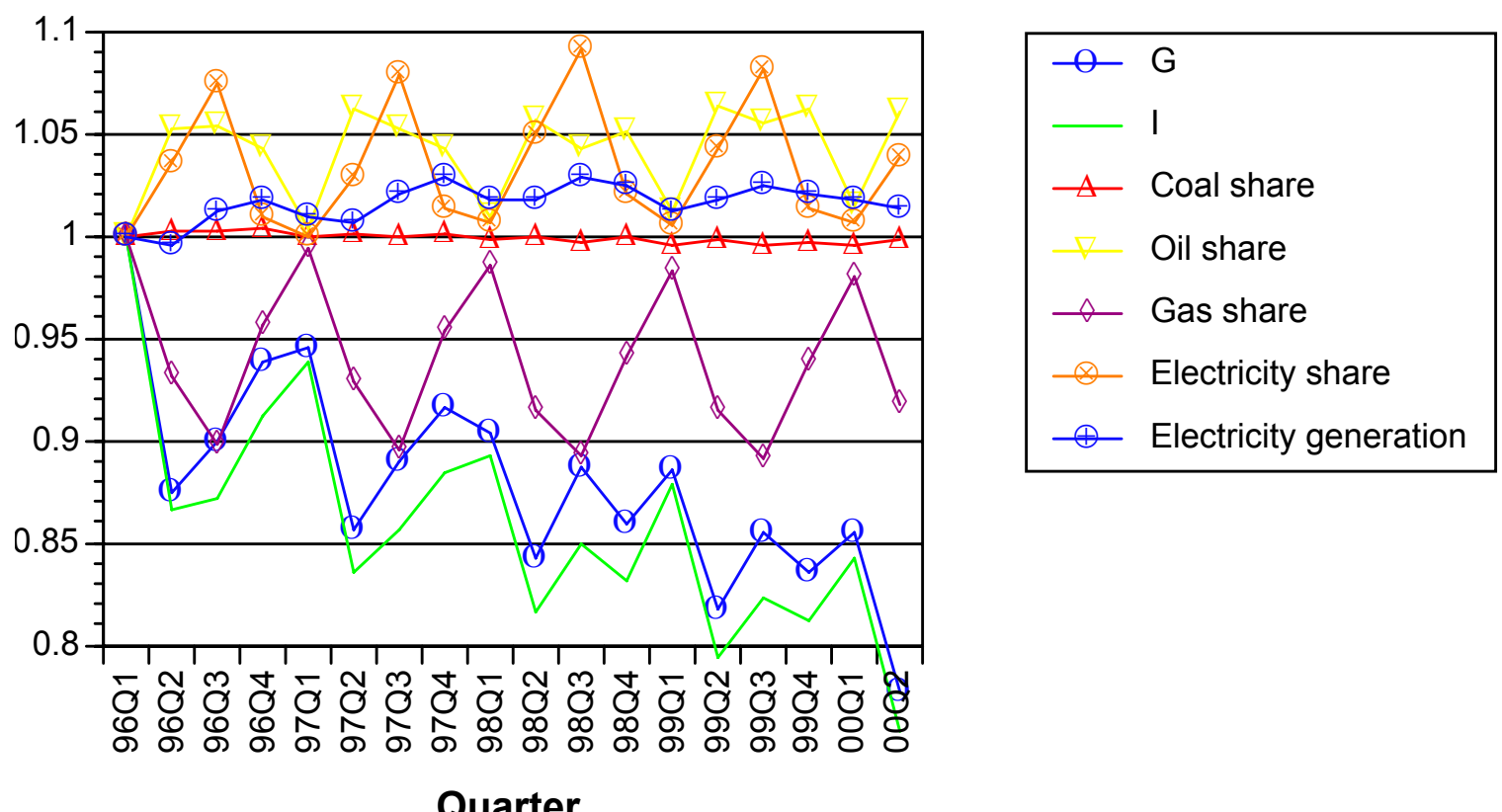

Figure 3.5. Standard Divisia decomposition of energy and carbon intensity has some problems when applied to quarterly data. The large decrease in the first quarter is carried through the entire study period, and the residual of decomposition is larger due to larger variations. 
Figure 3.6. Smoothed Divisia Indices

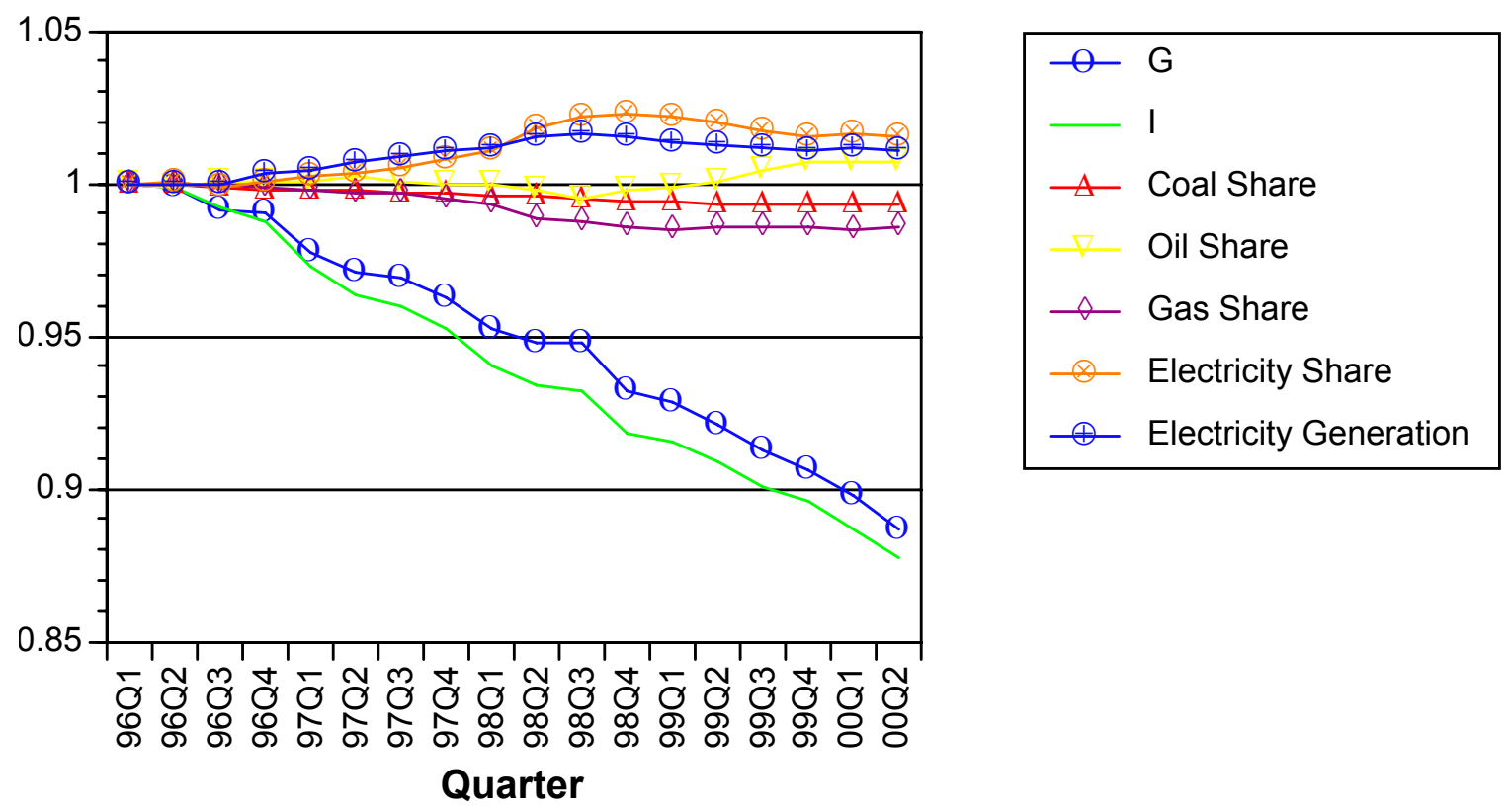

Figure 3.6. Smoothing resolves the problems with the standard Divisia decomposition. Both energy and carbon intensity ( $I$ and $G$ ) decreased $11-12 \%$ during the study period. The carbon intensity index $G$ is always higher than the energy intensity index $I$ indicating that the fuel mix has become more carbon intensive during this period. The electricity generation index indicates that the generation of electricity also became more carbon intensive, although this slight trend reversed after 1998. 
Figure 3.7. Smoothed Electricity Divisia Indices

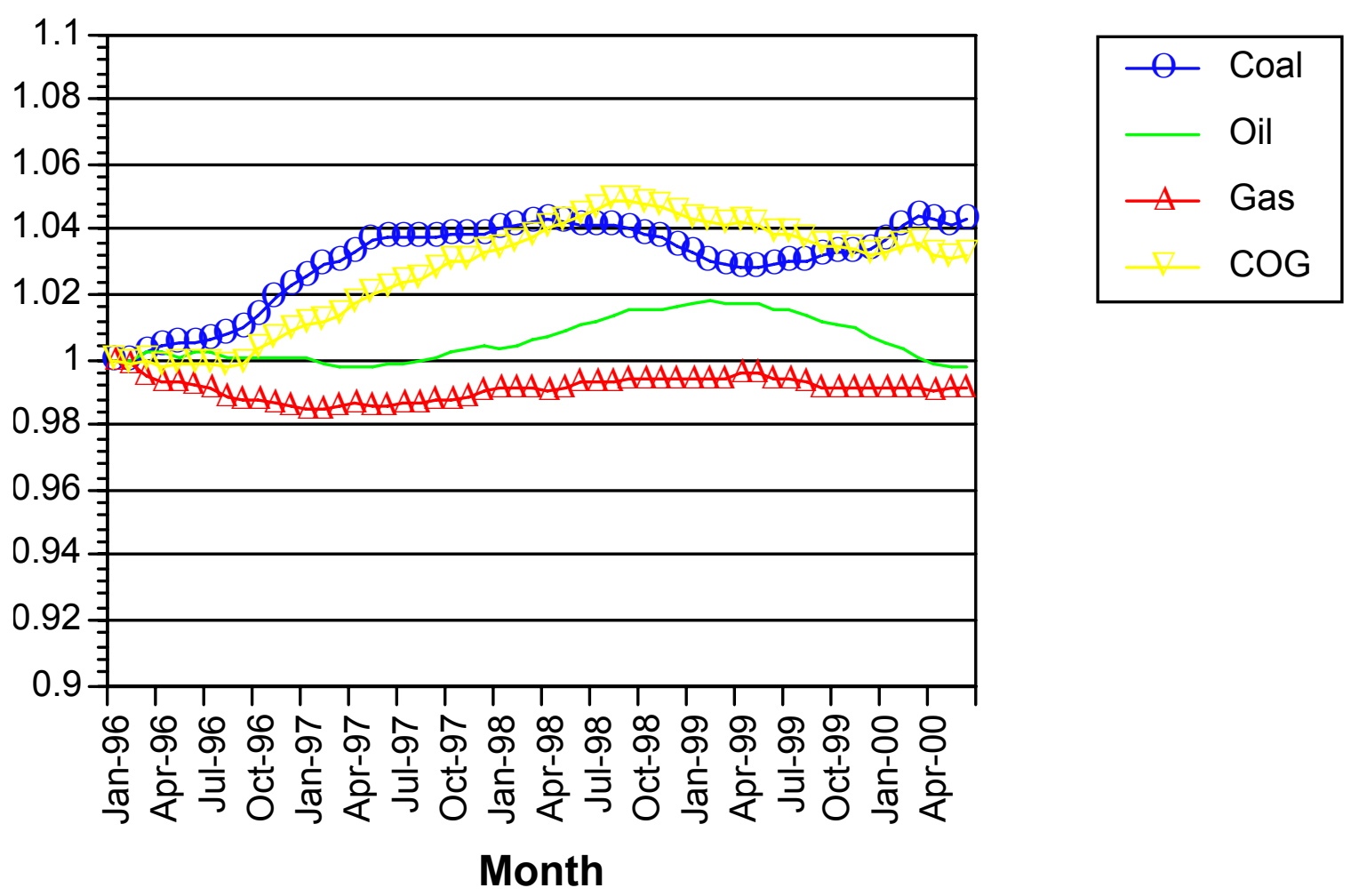

Figure 3.7. U.S. electricity generation became about 3\% more carbon intensive over the entire study period, increasing rapidly from October 1996, then decreasing less rapidly thereafter. The COG index is the product of the other three indices, representing the combined effect of changes in the fossil share. 
Figure 4.1. Smoothed, Weather Adjusted Divisia Indices

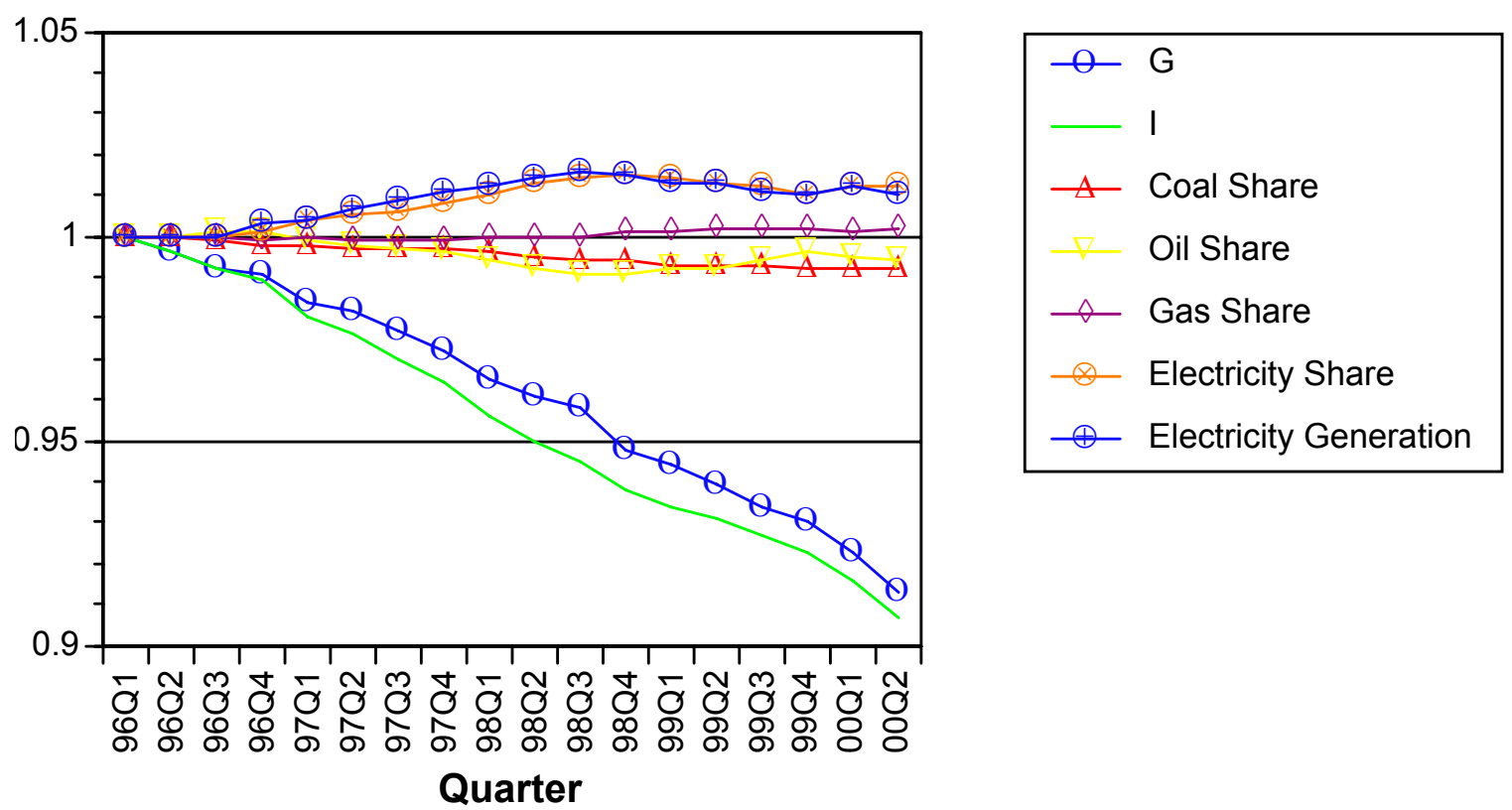

Figure 4.1. After the adjustment for hotter winters, energy and carbon intensity ( $I$ and $G$ ) are still seen to decrease $8-9 \%$ during the study period. 


\section{Figure 4.2. Fuel Mix and Weather Effects on Carbon Intensity}

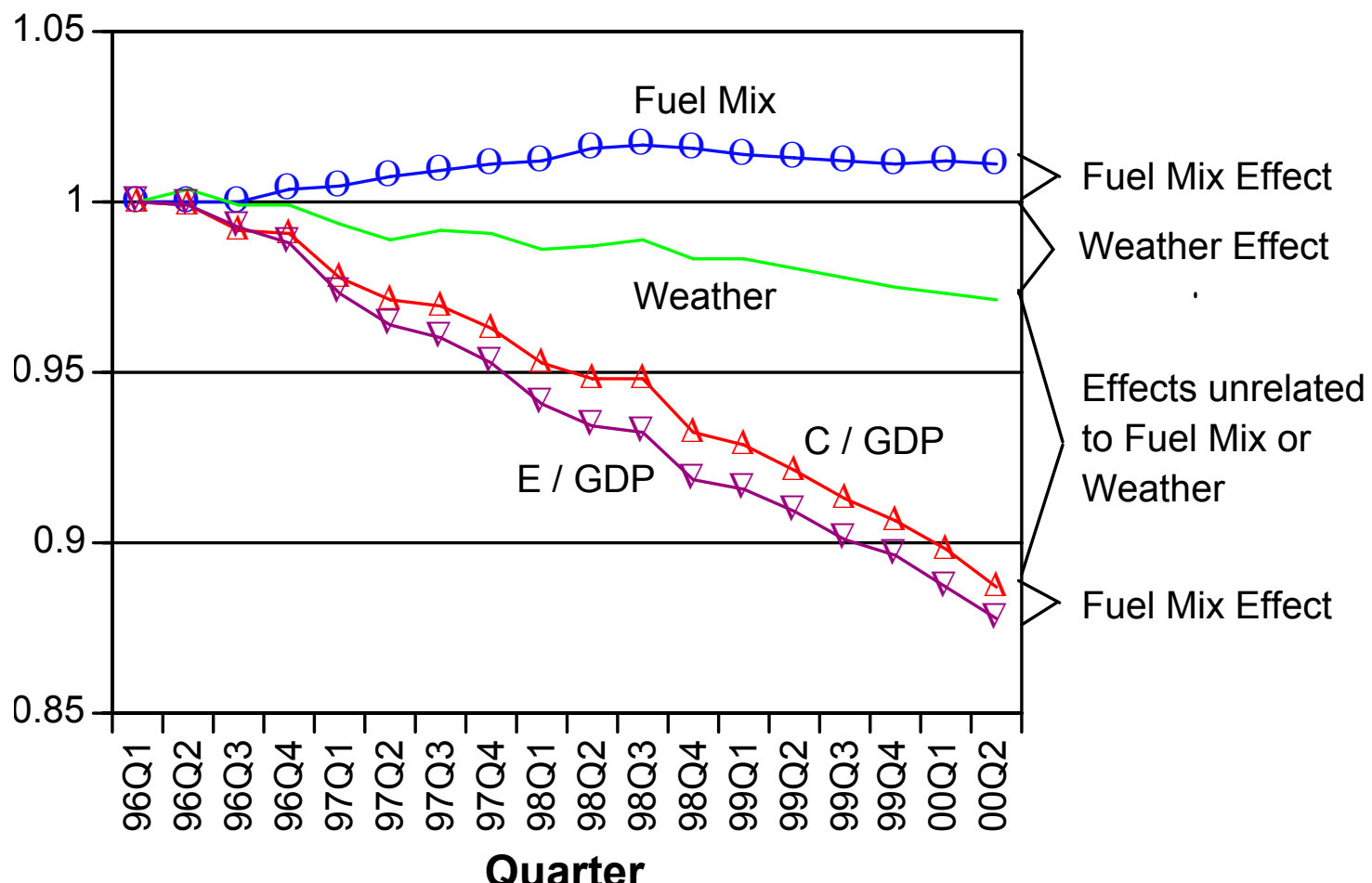

Figure 4.2. The observed energy and carbon intensity includes the charted weather effect. Hotter weather accounts for about one-quarter the observed decreases in energy and carbon intensity in the U.S. from 1996-2000, and changes in the fuel mix resulted in a slight increase in carbon intensity during this period. 
Figure 5.1. Smoothed Divisia Indices Including NUG

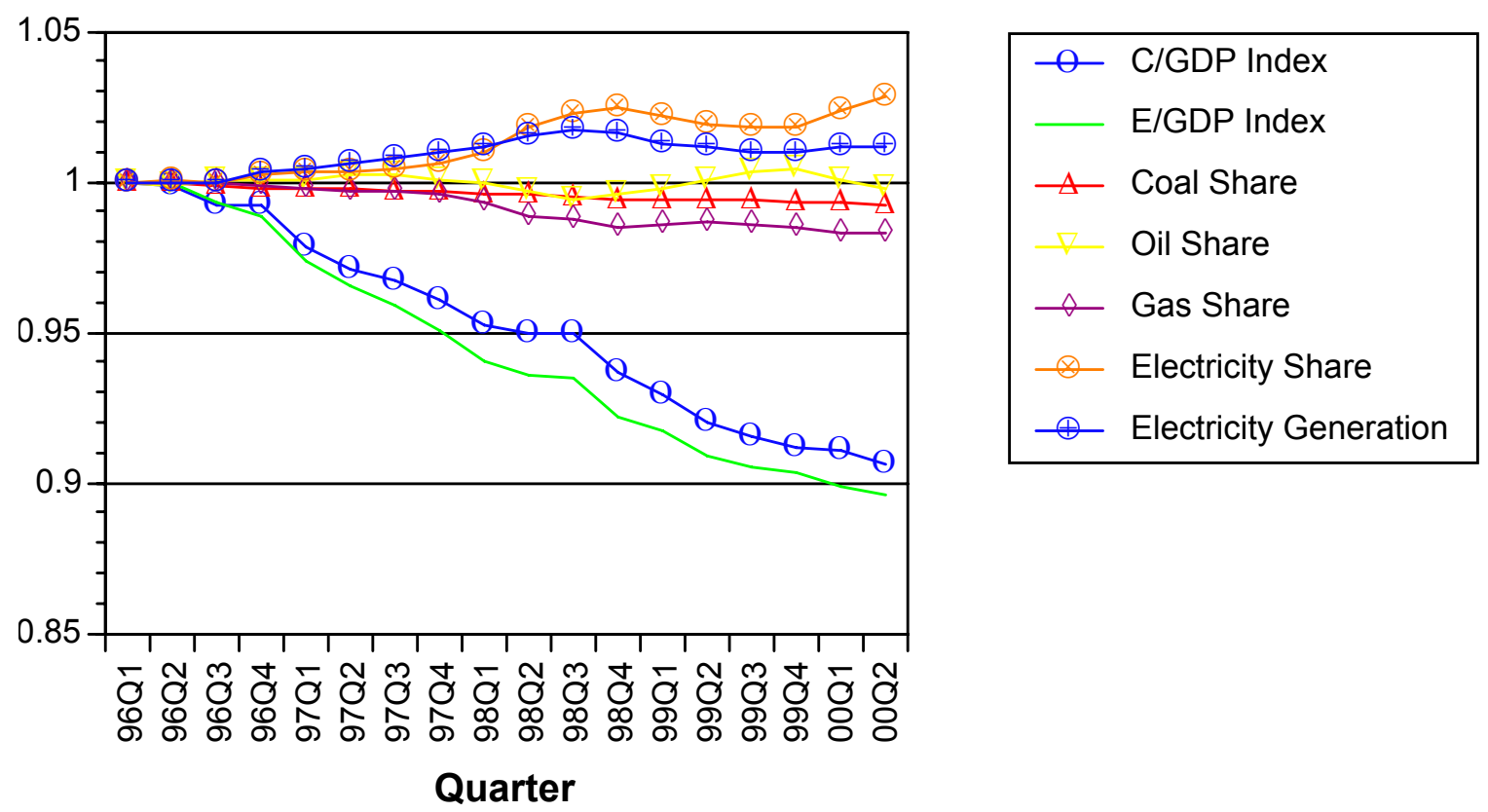

Figure 5.1. Including nonutility generation causes both carbon and energy intensity to decrease about $2 \%$ less over the entire study period, or about $0.4 \%$ slower per year. 


\section{REFERENCES}

Boyd, G.A., J. F. McDonald, et al., 1987, Separating the changing composition of U. S. manufacturing production from energy-efficiency improvements: A Divisia index approach, The Energy Journal 8(2), 77-96.

Boyd, G.A. and J.A. Laitner, 1999, Recent trends in U. S. energy intensity: An index number analysis, working paper, Argonne National Laboratory and U.S. Environmental Protection Agency.

Brynjolfsson, E. and L. M. Hitt, 2000, Computing Productivity: Firm-Level Evidence, working paper, MIT Sloan School of Management and University of Pennsylvania Wharton School, April.

Council of Economic Advisers (2000), Annual report of the Council of Economic Advisers, 2000 (Washington, DC; Government Printing Office).

Hakes, J.E., 2000, Statement before the Subcommittee on National Economic Growth, Natural Resources, and Regulatory Affairs, Committee on Government Reform, United States House of Representatives, February 2.

Howarth, R.B., L.J. Schipper, P.A. Duerr, S. Strom, 1991, Manufacturing energy use in 8 OECD countries - decomposing the impacts of changes in output, industry structure and energy intensity, Energy Economics 13 (2), 135-142.

Jorgenson, D.W. and K.J. Stiroh, 1999, Information Technology and Growth, working paper.

Jorgenson, D.W. and K.J. Stiroh, 2000, Raising the speed limit: U. S. economic growth in the information age, working paper, Harvard University and Federal Reserve Bank of New York.

Krackeler, T., L.J. Schipper, O. Sezgen, 1998, Carbon dioxide emissions in OECD service sectors: The critical role of electricity use, Energy Policy 26 (15), 1137-1152.

Oliner, S.D. and D.E. Sichel, 2000, The resurgence of growth in the late 1990s: Is information technology the story? working paper, Federal Reserve Board, Washington DC.

Romm, J., A.H. Rosenfeld, and S. Herrmann, 1999, The Internet economy and global warming: A scenario of the impact of e-commerce on energy and the environment, Version1.0, (Washington, DC: The Center for Energy and Climate Solutions).

Romm, J., 2000, The Internet and the new energy economy, (Washington, DC: The Center for Energy and Climate Solutions).

Stiroh, K.J., 1998, Computers, productivity, and input substitution, Economic Inquiry 36 
(2), 175-191.

Unander, F., S. Karbuz, L.J. Schipper, M. Khrushch, et al., 1999, Manufacturing energy use in OECD countries: Decomposition of long-term trends. Energy Policy 27 (13), 769778.

US DOE-EIA (U. S. Department of Energy Energy Information Administration), 2000a, Monthly energy review July 2000 (EIA Office of Energy Markets and End Use, DOE/EIA-0035(2000/07)).

US DOE-EIA (U. S. Department of Energy Energy Information Administration), 2000b, Emissions of Greenhouse Gases in the United States 1999 (EIA Office of Integrated Analysis and Forecasting, DOE/EIA-0573(99)).

US DOE-EIA (U. S. Department of Energy Energy Information Administration), 2000c, Electric Power Annual 1999: Volume II (Office of Coal, Nuclear, Electric and Alternate Fuels, DOE/EIA-0348(99)/2). 